alluvial soils), ba-kati (terra firme, lands that do not flood) and ba-rarara (forest with intermittent openings). Kayapo villages are sited to have access to a variety of these ecological zones, and the patterns of field ownership read like something from a current behavioural ecology text: although some fields are selected from $b a$ $k a t i$, others are carved from ba-epti because the better yields offset the unpredictable losses due to flooding; chiefs' fields and womens' collective fields are usually planted in such a way as to minimize total crop loss for any one family group. Not only do the Kayapo utilize some 250 plant species for their fruits, along with several hundred others for their nuts and tubers, but they also practice a transitional form of cultivation. In addition to cultivated plots near the villages, men on hunting treks rely on 'islands of resources' along their vast network of interlinked forest trails; these 'forest fields' are maintained by collecting plants during the day's travels and then replanting them near established campsites. At least 54 species of these semi-domesticated plants are used in the forest fields.

The Amazonian Indians also know their animals: "every significant detail of the life habits of animals is part of [the] hunter's knowledge, including the sound of its cry, its preferred foods, its excrement, its scents, the teeth marks it makes on fruit etc" 7 . Beyond this, the Kayapo practice a transitional form of domestication of animals. Thus, they deliberately stack the remains of banana and palm plants near villages to attract adult beetles that lay eggs in such refuse; in due course, the Indians know when to collect the tasty and nutritious grubs that mature from the eggs. The Kayapo further recognize some 54 species of stingless bees and 2 species of stinging bees: some of these are cultivated for honey and beeswax, and other species are cultivated (in rotting logs in holes dug in fields) as pollinators to increase crop yield.

Although little is known about the medicinal and other properties of the Kayapo's cultivars, at least two merit mention. The red seeds of urucu (Bixa orellana) are used to flavour foods and also as the main ingredient in body paint. Red body paint is widespread for adornment throughout Amazonia, but Posey also found urucu "to be an effective natural insect repellant with a significant reduction (as much as 84 per cent) in insect bites when painted on the body" 6 . The wild ginger madn-tu (Zinziber) is used - apparently with some effect - as a medicine against intestinal parasites.

Posey takes to task the common misconception that fields cultivated under slash-and-burn agriculture are totally abandoned after a few years. Kayapo 'abandoned' fields continue to produce harvests of yams and taro for 5-6 years, bananas for $12-15$ and $u r u c u$ for 20 years or more. The reforestation sequence also produces a variety of foods that attract game in artificially high densities, and this phenomenon is also exploited. The Kayapo "thus do not have a clearcut demarcation between fields and forest, nor between wild and domesticated. Rather they have a more general system for classification of ecological resources that forms a continuum between wild and domestic ones, all of which figure into integrated management strategies" 6 .

Posey also tells some fascinating tales of the way myth and ritual interweave with natural history facts. One example must suffice. The myth: the little red ants are gentle like women and they are the relative/friend of the manioc; this is why women use the little red ant to mix with urucu to paint their faces in the maize festival; the little red ant is the guardian of the field. The facts: manioc has extrafloral nectaries that attract the ants, which in turn trim away any bean vines that would prevent the new and fragile manioc stems from growing; the beans can climb on the maize, which is sturdy enough to shoot up undamaged; and the leguminous beans help fertilize the total crop. Thus, the coevolutionary relation of ants to the maniocmaize-bean system does indeed facilitate the women's work.

It is tempting to go beyond this, seeing such myth and ritual as functioning to regulate the Indians' use of natural resources. Although this may sometimes be so, I do not always find Posey's argument compelling: the Kayapo 'belief system' may simply serve to describe the world, rather than to manipulate it. Even so, such finely-nuanced description puts these people closer to the contributors to Nature than is commonly conceded.

\footnotetext{
1. Goodland, R.J.A. \& Irwin, H.S. Amazon Jungle: Green Hell to Red Desert? (Elsevier, New York, 1976).

Dobyns, H.F. Current Anthropology 7, 395 (1966)

3. Myers, T. Ethnohistory 21, 135 (1974).

4. Myers, $\mathrm{T}$. in Networks of the Past: Regional Interaction in Archaeology (eds Francis, P.D., Kense F.J. \& Duke, P.G.) 84 (Chacmool Press, Calgary, 1981)

5. Smith, N.J.H. Ann. Assoc. Am. Geogr. 70, 553(1980).

6. Posey, D.A. Ciencia e Cultura 35, 877 (1983).

Carneiro, R. in Native South Americans (ed. Lyon. P. arneiro, $R$. in Native South
(Little-Brown, Boston, 1974).
}

Robert M. May is Class of 1877 Professor of Zoology at Princeton University, New Jersey 08544, USA.

\title{
Nomenclature Code for Spanish names of birds
}

\section{from I.F. Aguillo and M. Fernandéz-Cruz}

ALTHOUGH publication of the International Code of Zoological Nomenclature was one of the most important achievements of modern taxonomy, vernacular nomenclatures remain useful as a communication tool; common names often hold a lot of information, as they represent a particular aspect of the relationship between man and his environment. The use of vernacular names is particularly common in the case of ornithology, a science with a high number of amateurs and much non-scientific literature. In that sense, ornithologists use both common and scientific names in their papers, giving special value to the former as an informative tool.

There is a great vernacular richness associated with birds, in every language and region of the world. The amount of information available is so large and varied, that quite often it is necessary to accept widely used names that are not as informative as they could be. This is not the case with the Spanish-speaking community of ornithologists, probably because the scientific infrastructure of the regions and the ornithological bibliography available in Spanish are very scarce. Thus the situation is favourable for the vernacular nomenclature of birds to be modified so that the names are more meaningful.

Since there are very few lists with accepted names in Iberoamerica, it will first be necessary to make a checklist to be used as a reference by all of the members of the community. Such a project has already been launched but its success will require the international cooperation of all 20 or so countries integrated in this community. The ultimate aim is to produce a system of common names for the Iberoamerican and European avifaunas, based on associative and meaningful names.

General agreement has led to the proposal for a unified Code of Spanish common names which states the rules for deriving the new nomenclature. Although its criteria are inspired by the International Code of Zoological Nomenclature, informative names will be favoured over priority ones. Names will be brief and easy to write and pronounce; and will be selected on the basis of how informative they are.

The unified nomenclature will be binominal. The first word will be the 'generic name' which refers to all those species that can be grouped in accordance with taxonomical, morphological or historical-usage criteria. Preferably, the name should be derived from the vernacular roots of the community people, adapting it to the Spanish language. In other cases, the name will include information about ecology and ethology of the bird, but not morphological information. The 'specific name' will follow as an adjective, will characterize each species, and represent it in every way. This name will include information about the bird's morphology and appearance, geographical distribution and so on.

The Code and details of the proposed unification project, in Spanish, are available from the authors at: Cátedra de Vertebrados, Facultad de Biologia, Ciudad Universitaria, 28040 Madrid, Spain. 